\title{
Associations between intimate partner violence profiles and mental health among low-income, urban pregnant adolescents
}

Jordan L. Thomas ${ }^{1 *} \mathbb{B}$, Jessica B. Lewis², Isabel Martinez², Shayna D. Cunningham², Moiuri Siddique², Jonathan N. Tobin ${ }^{3,4}$ and Jeannette R. Ickovics ${ }^{2}$

\begin{abstract}
Background: Intimate partner violence (IPV) during pregnancy is associated with adverse maternal and child health outcomes, including poor mental health. Previous IPV research has largely focused on women's victimization experiences; however, evidence suggests young women may be more likely to engage in bilateral violence (report both victimization and perpetration) or perpetrate IPV (unilateral perpetration) during pregnancy than to report being victimized (unilateral victimization). This study examined prevalence of unilateral victimization, unilateral perpetration, and bilateral violence, and the association between these IPV profiles and mental health outcomes during pregnancy among young, lowincome adolescents.
\end{abstract}

Methods: Survey data were collected from 930 adolescents (14-21 years; 95.4\% Black and Latina) from fourteen Community Health Centers and hospitals in New York City during second and third trimester of pregnancy. Multivariable regression models tested the association between IPV profiles and prenatal depression, anxiety, and distress, adjusting for known predictors of psychological morbidity.

Results: Thirty-eight percent of adolescents experienced IPV during their third trimester of pregnancy. Of these, 13\% were solely victims, $35 \%$ were solely perpetrators, and $52 \%$ were engaged in bilateral violence. All women with violent IPV profiles had significantly higher odds of having depression and anxiety compared to individuals reporting no IPV. Adolescents experiencing bilateral violence had nearly 4-fold higher odds of depression (OR=3.52, 95\% Cl: 2 . $43,5.09)$ and a nearly 5-fold increased likelihood of anxiety ( $\mathrm{OR}=4.98,95 \% \mathrm{Cl}: 3.29,7.55)$. Unilateral victims and unilateral perpetrators were also at risk for adverse mental health outcomes, with risk of depression and anxiety two- to three-fold higher, compared to pregnant adolescents who report no IPV. Prenatal distress was higher among adolescents who experienced bilateral violence $(\mathrm{OR}=2.84,95 \% \mathrm{Cl}: 1.94,4.16)$ and those who were unilateral victims $(\mathrm{OR}=2.21,95 \% \mathrm{Cl}: 1.19,4.12)$.

Conclusions: All violent IPV profiles were associated with adverse mental health outcomes among pregnant adolescents, with bilateral violence having the most detrimental associations. Comprehensive IPV screening for both victimization and perpetration experiences during pregnancy is warranted. Clinical and community prevention efforts should target pregnant adolescents and their partners to reduce their vulnerability to violence and its adverse consequences.

Trial registration: ClinicalTrials.gov, NCT00628771. Registered 29 February 2008.

Keywords: Intimate partner violence, Pregnancy, Adolescents, Bilateral violence, Depression, Mental health

\footnotetext{
* Correspondence: thomasj|@ucla.edu

'Department of Psychology, University of California, Los Angeles (UCLA), Los

Angeles, CA, USA

Full list of author information is available at the end of the article
}

(c) The Author(s). 2019 Open Access This article is distributed under the terms of the Creative Commons Attribution 4.0 International License (http://creativecommons.org/licenses/by/4.0/), which permits unrestricted use, distribution, and reproduction in any medium, provided you give appropriate credit to the original author(s) and the source, provide a link to the Creative Commons license, and indicate if changes were made. The Creative Commons Public Domain Dedication waiver (http://creativecommons.org/publicdomain/zero/1.0/) applies to the data made available in this article, unless otherwise stated. 


\section{Introduction}

Intimate partner violence (IPV) is a pervasive public health problem, impacting an estimated 4.7 million women and 5.4 million men annually [1]. Adolescent women are at particularly high risk, with nearly $70 \%$ of IPV victims experiencing their first IPV incident before age 25, and nearly one quarter before age 18 [1]. Pregnant adolescents have significantly higher rates of IPV than older mothers and their non-pregnant peers [2-7]. Pregnant adolescents are engaged simultaneously in the developmental tasks of adolescence and the transition to parenthood-both of which are stressful, and likely increase their vulnerability [8-10].

Among both adolescents and adult women, IPV during pregnancy is associated with adverse maternal and child health outcomes including psychological morbidity [5, 6, 11-16], pregnancy complications (e.g., vaginal bleeding, kidney infection, urinary tract infection, low gestational weight gain, preterm birth, low birth weight) [17-23], and risky perinatal health behaviors [22-30]. Research has shown that low-income pregnant and parenting adolescents are particularly vulnerable to the burden of postpartum depressive symptoms [7]. Although findings have been inconsistent [31], some studies suggest there are higher rates of perinatal depression and other adverse mental health outcomes among racial/ethnic minority women $[32,33]$. In addition, Black and Latina women have a higher twelve-month prevalence of rape, physical violence or stalking by an intimate partner than do white women [34], indicating this population may be particularly vulnerable to IPV and its related health outcomes [35].

Historically, IPV studies have focused largely on women's victimization experiences and outcomes [36]. However, evidence suggest that more than one-half of reported IPV could be categorized as bilateral, involving victimization and perpetration by both partners [37]. As a result, more recent research has begun to examine distinct profiles of intimate partner violence (i.e., unilateral victimization, unilateral perpetration, bilateral violence) and their correlates [38-42]. The limited studies of pregnant adolescents consistently find that more young women report perpetrating IPV during pregnancy than report being victimized [18, 40, 41, 43-45]. Perpetration of IPV has been linked to adverse mental health outcomes for women in previous studies [18, 38, 43, 45]. Moreover, those in bilaterally violent relationships may be at highest risk for adverse maternal and child outcomes $[18,40]$. More research on differing IPV profiles is needed in diverse populations and settings to inform screening and intervention strategies.

The objectives of this study are to (1) assess the prevalence of unilateral victimization, unilateral perpetration, and bilateral violence; and (2) determine whether these
IPV profiles are differentially associated with depression, anxiety, and prenatal distress during pregnancy among young, low-income adolescents. We hypothesized that bilateral violence would be associated with the greatest risk of adverse mental health consequences.

\section{Methods \\ Participants}

Data for this study were obtained from a cluster randomized trial of group prenatal care designed to improve maternal-child health and reduce HIV risk behaviors [46]. Pregnant adolescents aged 14 to 21 years $(N=$ 1233) were recruited from 14 Community Health Centers and hospital obstetric outpatient settings in New York City between 2008 and 2011, with follow-up data collection completed in 2012. To participate, women had to be less than 24 weeks gestation at study entry, not at high-risk obstetrically, and fluent in either English or Spanish. The cohort for this secondary data analysis is limited to adolescents with complete data on IPV during the third trimester of pregnancy, resulting in an analytic sample of $N=930$ participants. Those excluded from this secondary data analysis were slightly older ( $\mathrm{M}$ $=18.84$ years, $\mathrm{SD}=1.66)$ than those included $(\mathrm{M}=18.62$ years, $\mathrm{SD}=1.75$ ) and were less likely to have been born outside the United States. There were no other significant sociodemographic differences.

\section{Procedures}

Participants completed structured interviews via audiohandheld assisted personal interview technology at four points across the perinatal period, including the second and third trimester and six and twelve months postpartum. Interviews were approximately forty minutes and were completed in either English or Spanish. Analyses for this paper use data collected during the second (1424 weeks gestation) and third (32-42 weeks gestation) trimesters of pregnancy. Participants were paid $\$ 20$ for each interview. All procedures were approved by Institutional Review Boards (IRBs) at Yale University, Clinical Directors Network, and each clinical site.

\section{Primary predictor variable \\ Intimate partner violence}

IPV profiles for participants were created, using data from an adapted form of the Revised Conflict Tactics Scale [47] collected during their third trimester of pregnancy. Participants were asked to self-report the frequency of both victimization and perpetration experiences related to psychological (e.g., insult, swear, threaten), physical (e.g., push, grab, shove, slap, kick, bite punch, beat up, burn, choke), and sexual (e.g., forced sex, forced sexual acts) violence in their romantic relationships since their baseline (second trimester) interview. Individual item responses 
were coded dichotomously (yes/no) to identify any experience of IPV for each item. Separate variables were then created for each type of IPV (e.g., psychological, physical, sexual). Following previous research [30, 48, 49], responses were then categorized by experiences of any IPV victimization and any IPV perpetration. Using these dichotomous variables of victimization and perpetration, a new variable was created to represent four "intimate partner violence [IPV] profiles": (1) participants who reported no IPV victimization and no IPV perpetration (no IPV); (2) participants who reported IPV victimization but no IPV perpetration (unilateral victimization); (3) participants who perpetrated IPV and who reported no IPV victimization (unilateral perpetration); and (4) participants who reported both IPV victimization and IPV perpetration (bilateral violence).

\section{Dependent variables}

\section{Depression}

Depression was measured using the Center for Epidemiologic Studies Depression Scale (CES-D) [50]. As in prior studies of pregnant women [31], five somatic items were excluded from the 20-item scale to avoid overlap with pregnancy symptoms (e.g., changes in appetite or sleep). This affect-only adaptation includes 15 items regarding frequency of depressed mood (e.g., "feel depressed," "feel lonely") in the past week. Responses include less than one day (0), one to two days (1), three to four days (2) and five to seven days (3). Responses were reverse coded as needed, and summed to create a composite score for depression where greater scores indicated higher levels of depressive symptoms (range 045). A cutoff of greater than or equal to 16 is typically used to classify cases of depression for the full CES-D (range 0-60). For this study, participants with a CES-D score greater than or equal to 12 were classified as clinically depressed to account for truncated version of the scale (i.e., ratio based on maximum possible total score). Similar approaches have been used among other studies of young pregnant and postpartum couples [51,52].

\section{Anxiety}

Anxiety was measured using the Generalized Anxiety Disorder Scale (GAD-7) [53]. The GAD-7 includes seven items for self-reporting frequency of anxiety-related problems in the previous two weeks. Items are summed and result in a composite score ranging from 0 to 21, with higher scores indicating higher levels of anxiety-related problems. As per clinical guidelines, a score of greater than or equal to 10 was used to identify cases of moderate anxiety [53].

\section{Prenatal distress}

Prenatal distress was measured using the Revised Prenatal Distress Questionnaire (PDQ) [54, 55]. Participants were asked "how much are you bothered, worried, or upset" about 17 issues associated specifically with pregnancy (e.g., low energy, physical symptoms such as nausea or backaches, changes in weight/body shape, and taking care of the newborn baby) on a three-point scale ranging from not at all (0) to very much (2). Responses were summed to create a total prenatal-specific distress score, and following previous research [56], dichotomized based on the median split (11) to represent high and low prenatal distress in the sample. Other literature has reported similar mean values (9) among comparable study samples [57].

\section{Covariates}

Data obtained from participants included the following covariates known to be associated with depression, anxiety, or pregnancy distress: age, education (some high school, high school graduate, some college), employment status (employed, unemployed), relationships status (married or living together versus single/never married, separated/divorced, widowed), nativity (US versus foreign born), race/ethnicity (Hispanic/Latina, non-Latina Black, Other), and parity (nulliparous versus not).

\section{Analyses}

Descriptive statistics (means, frequencies) were calculated using ANOVA and chi-square tests to determine if women with different IPV profiles differed significantly on sociodemographic or psychosocial characteristics. Bivariate and multivariable logistic regression models were conducted to determine likelihood of depression, anxiety, and prenatal distress for each IPV profile with "no IPV" as the reference category. All covariates were evaluated as potential confounders in multivariable models. Variables with significance of $\alpha=0.05$ or lower were kept in multivariable models. Analyses also controlled for study condition (i.e., assignment to group versus individual care). Analyses were completed using SAS 9.4 and IBM SPSS 25 software.

\section{Results}

\section{Sample characteristics}

Table 1 contains the distribution of sociodemographic and psychosocial characteristics in this sample by IPV profile. Overall, $38.8 \%(n=361)$ of the sample reported experiencing some form of IPV during the prenatal period. Of these, $13 \%$ were only victims, $35 \%$ were only perpetrators and $52 \%$ were engaged in bilateral violence as both victim and perpetrator. These relationships were further characterized by the type of violence (e.g., psychological, physical, and sexual) of that occurred. Bilaterally violent relationships had the highest rates of violence, regardless of type of violent act. Psychological violence was the most common across IPV profiles; $35 \%$ 
Table 1 Sample characteristics, \% (n) or M (SD)

\begin{tabular}{|c|c|c|c|c|c|c|}
\hline & $\begin{array}{l}\text { No Violence } \\
61.2(569)\end{array}$ & $\begin{array}{l}\text { Unilateral } \\
\text { Victimization } \\
5.2(48)\end{array}$ & $\begin{array}{l}\text { Unilateral } \\
\text { Perpetration } \\
13.5 \text { (126) } \\
\end{array}$ & $\begin{array}{l}\text { Bilateral Violence } \\
20.1(187)\end{array}$ & $\begin{array}{l}\text { Overall } \\
(N=930)\end{array}$ & $p$-value \\
\hline \multicolumn{7}{|l|}{ Age } \\
\hline Race/Ethnicity & & & & & & 0.001 \\
\hline Hispanic/Latina & $66.3(377)$ & $50.0(24)$ & $62.7(79)$ & $48.7(91)$ & $61.4(571)$ & \\
\hline Black, non-Latina & $29.5(168)$ & $41.7(20)$ & $31.7(40)$ & $45.5(85)$ & 33.7 (313) & \\
\hline Other $^{a}$ & $4.2(24)$ & $8.3(4)$ & $5.6(7)$ & $5.9(11)$ & $4.9(46)$ & \\
\hline Nativity & & & & & & 0.023 \\
\hline U.S. born & $59.9(341)$ & $62.5(30)$ & $65.9(83)$ & $72.2(135)$ & $63.3(589)$ & \\
\hline Foreign born & $40.1(228)$ & $37.5(18)$ & $34.1(43)$ & $27.8(52)$ & $36.7(341)$ & \\
\hline Education & & & & & & 0.519 \\
\hline Some high school & $61.4(344)$ & $60.4(29)$ & $64.3(81)$ & $53.5(100)$ & $60.2(554)$ & \\
\hline High school graduate & $20.0(112)$ & $18.8(9)$ & $18.3(23)$ & $22.5(42)$ & $20.2(186)$ & \\
\hline Some college & $18.6(104)$ & $20.8(10)$ & $17.5(22)$ & $24.1(45)$ & $19.7(181)$ & \\
\hline Nulliparous & & & & & & 0.211 \\
\hline No & $15.9(86)$ & $17.0(8)$ & $11.5(14)$ & $10.4(19)$ & $14.2(127)$ & \\
\hline Yes & $84.1(455)$ & $83.0(39)$ & $88.5(108)$ & $89.6(164)$ & $85.8(766)$ & \\
\hline Employment & & & & & & 0.209 \\
\hline Unemployed & $80.0(453)$ & $85.4(41)$ & $75.2(94)$ & 74.7 (139) & 78.6 (727) & \\
\hline Employed & $20.0(113)$ & $14.6(7)$ & $24.8(31)$ & $25.3(47)$ & $21.4(198)$ & \\
\hline Main source of financial support & & & & & & 0.051 \\
\hline Self & $18.5(105)$ & $20.8(10)$ & $21.6(27)$ & $18.8(35)$ & $19.1(177)$ & \\
\hline Partner & $32.5(183)$ & $29.2(14)$ & $21.6(27)$ & $25.8(48)$ & $29.3(272)$ & \\
\hline Parent & $33.6(191)$ & $39.6(19)$ & $46.4(58)$ & $34.4(64)$ & $35.8(332)$ & \\
\hline Other & $15.7(89)$ & $10.4(5)$ & $10.4(13)$ & $21.0(39)$ & $15.7(146)$ & \\
\hline Relationship status & & & & & & 0.020 \\
\hline Married or living together & $45.2(249)$ & $37.8(17)$ & $39.2(49)$ & $32.4(59)$ & $41.4(374)$ & \\
\hline $\begin{array}{l}\text { Other relationship (single/never } \\
\text { married, sep/divorced, widowed) }\end{array}$ & $54.8(302)$ & $62.2(28)$ & $60.8(76)$ & $67.6(123)$ & $58.6(529)$ & \\
\hline Depression & & & & & & $<0.0001$ \\
\hline Not depressed & $67.8(386)$ & $45.8(22)$ & $53.2(67)$ & $39.6(74)$ & $59.0(549)$ & \\
\hline Depressed & $32.2(183)$ & $54.2(26)$ & $46.8(59)$ & $60.4(113)$ & $41.0(381)$ & \\
\hline Anxiety & & & & & & $<0.0001$ \\
\hline No & $88.4(502)$ & $78.7(37)$ & $78.6(99)$ & $61.0(114)$ & $81.0(752)$ & \\
\hline Yes & $11.6(66)$ & $21.3(10)$ & $21.4(27)$ & $39.0(73)$ & $19.0(176)$ & \\
\hline Prenatal distress & & & & & & $<0.0001$ \\
\hline Low & $52.5(297)$ & $33.3(16)$ & $45.6(57)$ & $27.0(50)$ & $45.5(420)$ & \\
\hline High & 47.5 (269) & $66.7(32)$ & $54.4(68)$ & 73.0 (135) & $54.5(504)$ & \\
\hline Type of violence & & & & & & $<0.0001$ \\
\hline Physical & - & 37.5 (18) & $44.4(56)$ & 72.7 (136) & $22.6(210)$ & \\
\hline Verbal & - & $87.5(42)$ & $83.3(105)$ & $96.3(180)$ & $35.2(327)$ & \\
\hline Sexual & - & $14.6(7)$ & $1.6(2)$ & $15.5(29)$ & $4.1(38)$ & \\
\hline
\end{tabular}


of all violent relationships involved verbal acts of violence. Nearly one-quarter of all violent relationships involved physical acts of violence. Overall, sexual violence was uncommon, though it occurred most frequently in bilaterally violent relationships.

Overall, 41\% $(n=381)$ of the sample was depressed, $19 \%(n=176)$ reported anxiety, and $54.5 \%(n=504)$ reported high prenatal distress. Within IPV profiles, depression, anxiety, and prenatal distress were lowest among those with no IPV, followed by unilateral perpetrators, unilateral victims, and highest among those reporting bilateral violence.

\section{Association between IPV experiences and mental health outcomes}

In bivariate analyses, all violent IPV profiles had significantly higher odds of having depression, anxiety and pregnancy distress compared to individuals reporting no IPV. Relative to individuals experiencing no IPV, the odds of having depression $\left(\mathrm{OR}_{\mathrm{Bilat}} \mathrm{IPV}=3.22,95 \% \mathrm{CI}\right.$ : $2.29,4.53)$, anxiety $\left(\mathrm{OR}_{\text {Bilat } \mathrm{IPV}}=4.87,95 \% \mathrm{CI}: 3.30\right.$, $7.19)$, and prenatal distress $\left(\mathrm{OR}_{\text {Bilat IPV }}=2.98,95 \% \mathrm{CI}\right.$ : $2.08,4.29)$ were highest amongst the bilateral violence group for all outcomes.

Table 2 shows the unadjusted and adjusted results of the multivariable models for associations between IPV and mental health. Compared to individuals who experienced no IPV, the odds of having depression were more than 2-fold higher for unilateral perpetrators $(\mathrm{OR}=2.05$, 95\% CI: 1.36, 3.09), 3-fold higher for unilateral victims $(\mathrm{OR}=3.03,95 \% \mathrm{CI}: 1.60,5.73)$, and almost 4-fold higher for those reporting bilateral violence $(\mathrm{OR}=3.52,95 \% \mathrm{CI}$ : $2.43,5.09$ ). All IPV profiles likewise had a significantly higher likelihood of reporting anxiety relative to individuals who experienced no IPV: a more than 2-fold increase for unilateral perpetrators $(\mathrm{OR}=2.14,95 \% \mathrm{CI}$ : $1.28,3.58)$ and unilateral victims $(\mathrm{OR}=2.22,95 \% \mathrm{CI}$ : $1.03,4.81)$, and a nearly 5 -fold increase for those reporting bilateral violence $(\mathrm{OR}=4.98,95 \% \mathrm{CI}: 3.29,7.55)$. A similar trend for prenatal distress was observed for unilateral victims and individuals who experienced bilateral violence. Unilateral victims were more than twice as likely $(\mathrm{OR}=2.62,95 \% \mathrm{CI}: 1.33,5.14)$ and individuals who experienced bilateral violence were almost 3 times more likely $(\mathrm{OR}=2.84,95 \% \mathrm{CI}: 1.94,4.16)$ to report prenatal distress compared to individuals who experienced no IPV. Unilateral perpetrators were not at increased risk for prenatal distress. $P$-values for all significant associations ranged from $p<0.05-p<0.0001$.

\section{Discussion}

Results of this study provide insight into the prevalence and correlates of physical, psychological and sexual IPV among pregnant adolescents. Prevalence of partner violence was high, with $38 \%$ of pregnant adolescents reporting some type of violence during pregnancy. Psychological violence was particularly common among violent relationships. Nearly 1 in 5 participants were involved in bilateral violence with their partner, placing the entire family at risk for adverse outcomes.

IPV among pregnant adolescents was associated with increased risk of adverse mental health outcomes for all violence profiles, regardless of victimization or perpetration status. Unilateral victims, perpetrators, and those who engaged in bilateral violence were all at significantly higher risk for depression and anxiety. Unilateral victims and those who engaged in bilateral violence were also at increased risk for prenatal distress; however, unilateral perpetrators were not. Prenatal distress measures concerns specific to pregnancy and baby wellness. It may be that fear of physical injury from IPV is driving increased prenatal distress for those whose IPV profiles include victimization. In this sample, nearly one-quarter of violent relationships were characterized by physical violence. Further, rates of psychological violence were higher among those whose IPV profiles included victimization relative to unilateral perpetrators. Psychological violence may include threats of bodily harm that may or may not be enacted. Thus, unilateral perpetrators do not have increased prenatal distress.

Adolescents engaging in bilateral violence during pregnancy had the greatest likelihood of reporting adverse mental health outcomes. Specifically, these pregnant adolescents were nearly four times more likely to experience depression, nearly five times more likely to experience anxiety, and almost three times as likely to

Table 2 Associations between overall IPV profile and mental health outcomes ${ }^{a}$

\begin{tabular}{|c|c|c|c|c|c|c|}
\hline & \multicolumn{2}{|l|}{ Depression } & \multicolumn{2}{|l|}{ Anxiety } & \multicolumn{2}{|l|}{ Prenatal distress } \\
\hline & $\overline{\mathrm{OR}}$ & AOR & $\overline{\mathrm{OR}}$ & AOR & $\overline{\mathrm{OR}}$ & $\mathrm{AOR}$ \\
\hline No violence & 1.00 (reference) & 1.00 (reference) & 1.00 (reference) & 1.00 (reference) & 1.00 (reference) & 1.00 (reference) \\
\hline Unilateral victimization & $2.49^{* *}(1.38,4.52)$ & $3.03^{* *}(1.60,5.73)$ & $2.06(0.98,4.32)$ & $2.22^{*}(1.03,4.81)$ & $2.21^{*}(1.19,4.12)$ & $2.62^{* *}(1.33,5.14)$ \\
\hline Unilateral perpetration & $1.86^{* *}(1.26,2.75)$ & $2.05^{* * *}(1.36,3.09)$ & $2.07^{* *}(1.26,3.41)$ & $2.14^{* *}(1.28,3.58)$ & $1.32(0.89,1.94)$ & $1.37(0.91,2.05)$ \\
\hline Bilateral violence & $3.22^{* * *}(2.29,4.53)$ & $3.52^{* * *}(2.43,5.09)$ & $4.87^{* * *}(3.30,7.19)$ & $4.98^{* * *}(3.29,7.55)$ & $2.98^{* * *}(2.08,4.29)$ & $2.84^{* * *}(1.94,4.16)$ \\
\hline
\end{tabular}

${ }^{a}$ Adjusted odds ratios (AOR) control for age, education, employment status, relationship status, intervention arm, nativity, parity and race/ethnicity ${ }^{*} p \leq 0.05{ }^{* *} p \leq 0.005{ }^{* * *} p \leq 0.0001$ 
experience prenatal distress relative to adolescents who did not experience IPV. Another study of more than 1000 high-risk African American pregnant women found that those in bilaterally violent relationships were at highest risk for depression [18]. Lewis and colleagues likewise recently documented pregnant adolescent couples with mutual IPV have the least healthy relationship (e.g., attachment anxiety, relationship equity) and psychological (e.g., depression, stress, hostility) characteristics [40]. The differential associations highlighted by each of these studies confirm the importance of screening adolescents for specific IPV profiles during pregnancy, since they are associated with varied risks for mental health.

Several factors may underlie these findings. Previous research has demonstrated that women engaging in violence often do so in the context of responding to partner-initiated violence $[58,59]$. Such retaliatory responses may be intensified during pregnancy, a time of heightened socioemotional, physiologic, and behavioral change. Pregnant women may feel protective of their unborn baby [60], and motivated to incite or reciprocate violence in their relationships. Relationship aggression may be especially pronounced among adolescent mothers due to specific developmental and contextual factors, including physical, psychological, and cognitive changes, increased stress, and the transition to parenting - all of which are psychologically taxing [58, 61], and require increased access to resources.

Notably, these findings confirm that both being a victim or perpetrator of violence in an intimate relationship impacts young women's mental health, and that bilateral violence engagement is especially psychologically harmful. It is well-established that poor mental health in pregnancy is associated with multiple adverse birth, neonatal, and infant outcomes [62, 63]. Mothers who experience depression or anxiety are more likely to engage in negative health-related behaviors and have difficulty managing infant distress [14]. Thus, the impact may extend far beyond the perinatal period, with adolescents who participate in bilateral violence at high risk for both adverse mental health in pregnancy and more long-term physical and mental health consequences [18].

Data examining women's perpetration of IPV have been critiqued throughout the literature for undermining the adverse asymmetrical effects partner violence has on women [38]. Bidirectionality of IPV does not indicate that men and women perpetrate violence for the same reasons or experience the same effects [64]. Yet, given the associations between perpetration and mental health found in this study and others [18, 38, 43, 45], it is critical to women's health to consider both perpetration and victimization experiences. Avenues for future research could include quantitative and qualitative studies that focus on adolescent couples' motivations for perpetration and other contextual factors of IPV in pregnancy.
There were several limitations to this study. The analysis focused on discrete acts of violence and did not capture severity, frequency, or other contextual or relational factors. Due to the cross-sectional design, we cannot make causal inferences about these associations. IPV was based on retrospective self-report by women only and thus is subject to social desirability bias and underreporting. Future work could include partner health outcomes or couple-level health indicators, as well. Our sample was largely comprised of pregnant Black and Latina adolescents and included only a small number of non-minority women, thereby limiting the generalizability of results to women of other races and ages. Future research could examine if associations between partner violence and mental health differ by race using larger and more representative study samples.

In contrast, important study strengths include clinicallyrelevant effects highlighting the impact of partner violence on young women's mental health. Additionally, few studies ask women about their own perpetration of violence. This study extends the evidence base for the relative impact of different IPV profiles on mental health. Future work should continue to build upon the terms used to describe these profiles (e.g., unilateral victimization, unilateral perpetration, and bilateral violence), as heterogeneity in IPV terminology across the literature may mask potential differences between studies and result in underestimations of effects.

The health care system represents a clear target for preventive intervention, as pregnant women have regular engagement with health care professionals throughout the perinatal period. This study provides further evidence of the need for comprehensive IPV screening as a national standard in prenatal care. Routine universal screening for IPV among women patients has been recommended by the American Congress of Obstetricians and Gynecologists and others [65-67], but existing screening tools do not comprehensively assess IPV. Emphasis on an exclusive "male perpetrator-female victim" paradigm in research and clinical treatment and prevention may be ineffective at reducing violence for pregnant adolescents. In addition to incorporating perpetration assessments into clinical screening tools, it may also be beneficial to incorporate screening and prevention efforts into other clinical and community interventions with adolescent couples and mothers (e.g., labor preparation, expecting parent skill development programs) [43].

\section{Conclusion}

Intimate partner violence is prevalent among women of reproductive age and has the potential to contribute to adverse mental health outcomes during pregnancy and beyond. Pregnant adolescents may experience distinct IPV profiles (e.g., unilateral IPV victimization, unilateral 
IPV perpetration, and bilateral violence), all of which are associated with adverse mental health. Bilateral violence, the most prevalent type of IPV, appears to be associated with greater depression, anxiety, and prenatal distress than unilateral forms of violence. Future research should assess risk factors that are associated with distinct profiles and types of IPV and investigate optimal intervention strategies to reduce both victimization and perpetration during pregnancy, a period during which couples may be motivated to engage in behavior change on behalf of their future family. A comprehensive understanding of the associations between IPV profiles and mental health is needed to tailor prevention and intervention strategies for young pregnant and parenting couples, mitigating health risks related to partner violence among this vulnerable population.

\section{Abbreviations \\ ANOVA: Analysis of variance; AOR: Adjusted odds ratio; CES-D: Center for Epidemiologic Studies Depression; Cl: Confidence interval; GAD: Generalized anxiety disorder; HIV: Human immunodeficiency virus; IPV: Intimate partner violence; IRB: Institutional Review Board; OR: Odds ratio; PDQ: Prenatal Distress Questionnaire}

\section{Acknowledgments}

Not applicable.

\section{Funding}

Funding for this work came from the National Institute of Mental Health (NIMH; linked R01s MH074399 [JRI] and MH074394 [JNT]). NIMH did not play a role in the study design, data collection and analysis, interpretation of results, or manuscript preparation.

\section{Availability of data and materials}

The datasets analyzed during the current study are available from the corresponding author on reasonable request.

\section{Authors' contributions}

JLT was the primary article author, with critical input and substantial revision from JL and SC. IM and JLT analyzed the data, with statistical consultation from $J \mathrm{~L}$ and SC. $J$ and JNT were the principal investigators of the trial from which these data are drawn. MS was involved in the design of the study and contributed to initial drafts of the manuscript. All authors contributed to edits and have read and approved the final version of the manuscript.

\section{Ethics approval and consent to participate}

This study was approved by Yale University (26962), and Clinical Directors Network (004-06), Bronx Lebanon Hospital Center (05 0808 02), Biomedical Research Alliance of New York (08-02-242(HHC)-202), Brookdale University Hospital and Medical Center (07-18), Brooklyn Hospital Center (624), Columbia University Medical Center (IRB-AAAD1707), Flushing Hospital (08/07-1), Lutheran Medical Center (53), and Public Health Solutions (032607). All participants provided written informed consent. The IRBs for 12 of the 14 study sites waived the parental informed consent requirement for participants aged 14-17, because the study was low risk and participants were independently consenting to their own prenatal care per New York State law. Thus, these IRBs considered these participants mature minors, able to independently provide informed consent for this study. Two of the 14 study sites' local IRBs required parental consent. For those participants, both parental informed consent and minor assent was obtained.

\section{Consent for publication}

Not applicable.

\section{Competing interests}

The authors declare that they have no competing interests.

\section{Publisher's Note}

Springer Nature remains neutral with regard to jurisdictional claims in published maps and institutional affiliations.

\section{Author details}

'Department of Psychology, University of California, Los Angeles (UCLA), Los Angeles, CA, USA. ${ }^{2}$ Yale School of Public Health, New Haven, CT, USA. ${ }^{3}$ Clinical Directors Network (CDN), New York, NY, USA. ${ }^{4}$ The Rockefeller University Center for Clinical and Translational Science, New York, NY, USA.

Received: 31 July 2017 Accepted: 21 March 2019

Published online: 26 April 2019

\section{References}

1. Black MC, Basile KC, Breiding MJ, Smith SG, Walters ML, Merrick MT, et al. The National Intimate Partner and sexual violence survey (NISVS): 2010 summary report. Atlanta, GA: National Center for Injury Prevention and Control, Centers for Disease Control and Prevention; 2011. https://www.cdc. gov/violenceprevention/pdf/nisvs_report2010-a.pdf. Accessed 1 June 2017

2. Saltzman LE, Johnson CH, Gilbert BC, Goodwin MM. Physical abuse around the time of pregnancy: an examination of prevalence and risk factors in 16 states. Matern Child Health J. 2003;7(1):31-43.

3. Shadigian EM, Bauer ST. Screening for partner violence during pregnancy. Int J Gynecol Obstet. 2004;84(3):273-80.

4. Roberto KA, McCann BR, Brossoie N. Intimate partner violence in late life: an analysis of national news reports. J Elder Abuse Negl. 2013;25(3):230-41.

5. Florsheim P, Sumida E, McCann C, Winstanley M, Fukui R, Seefeldt T, et al. The transition to parenthood among young African American and Latino couples: relational predictors of risk for parental dysfunction. J Fam Psychol. 2003;17(1):65-79.

6. Moffitt TE, E-Risk Team. Teen-aged mothers in contemporary Britain. J Child Psychol Psychiatry. 2002;43(6):727-42.

7. Seigel RS, Brandon AR. Adolescents, pregnancy, and mental health. J Pediatr Adolesc Gynecol. 2014;27(3):138-50.

8. Cowan C, Cowan P. When partners become parents: the big life change for couples. 1st ed. New York: Basic Books; 1999.

9. Lipsky S, Holt VL, Easterling TR, Critchlow CW. Police-reported intimate partner violence during pregnancy: who is at risk? Violence Vict. 2005;20(1):69-86.

10. Byrne DG, Davenport SC, Mazanov J. Profiles of adolescent stress: the development of the adolescent stress questionnaire (ASQ). J Adolesc. 2007; 30(3):393-416.

11. Valentine JM, Rodriguez MA, Lapeyrouse LM, Zhang M. Recent intimate partner violence as a prenatal predictor of maternal depression in the first year postpartum among Latinas. Arch Womens Ment Health. 2011;14(2):135-43.

12. Van Parys A, Deschepper E, Michielsen K, Galle A, Roelens K, Temmerman M, et al. Intimate partner violence and psychosocial health, a cross-sectional study in a pregnant population. BMC Pregnancy Childbirth. 2015;15:278.

13. Dunn LL, Oths KS. Prenatal predictors of intimate partner abuse. J Obstet Gynecol Neonatal Nurs. 2004;33(1):54-63.

14. Martin SL, Li Y, Casanueva C, Harris-Britt A, Kupper LL, Cloutier S. Intimate partner violence and women's depression before and during pregnancy. Violence Against Women. 2006;12(3):221-39.

15. Mahenge B, Likindikoki S, Stöckl H, Mbwambo J. Intimate partner violence during pregnancy and associated mental health symptoms among pregnant women in Tanzania: a cross-sectional study. BJOG. 2013;120(8):940-6.

16. Lindhorst $\mathrm{T}$, Oxford $\mathrm{M}$. The long-term effects of intimate partner violence on adolescent mothers' depressive symptoms. Soc Sci Med. 2008;66(6):1322-33.

17. Silverman JG, Decker MR, Reed E, Raj A. Intimate partner violence victimization prior to and during pregnancy among women residing in 26 U.S. states: associations with maternal and neonatal health. Am J Obstet Gynecol. 2006;195(1):140-8.

18. Shneyderman Y, Kiely M. Intimate partner violence during pregnancy: victim or perpetrator? Does it make a difference? BJOG. 2013;120(11):1375-85.

19. Alhusen JL, Ray E, Sharps P, Bullock L. Intimate partner violence during pregnancy: maternal and neonatal outcomes. J Women's Health. 2015;24(1):100-6.

20. Donovan BM, Spracklen CN, Schweizer ML, Ryckman KK, Saftlas AF. Intimate partner violence during pregnancy and the risk for adverse infant outcomes: a systematic review and meta-analysis. BJOG. 2016;123(8):1289-99.

21. Moraes $C L$, Amorim $A R$, Reichenheim ME. Gestational weight gain differentials in the presence of intimate partner violence. Int J Gynaecol Obstet. 2006;95(3):254-60. 
22. McFarlane J, Parker B, Soeken K. Abuse during pregnancy: associations with maternal health and infant birth weight. Nurs Res. 1996;45(1):37-42.

23. Beydoun HA, Tamim H, Lincoln AM, Dooley SD, Beydoun MA. Association of physical violence by an intimate partner around the time of pregnancy with inadequate gestational weight gain. Soc Sci Med. 2011;72(6):867-73.

24. Chambliss LR. Intimate partner violence and its implication for pregnancy. Clin Obstet Gynecol. 2008;51(2):385-97.

25. Cha S, Masho SW. Discussions about intimate partner violence during prenatal care in the United States: the role of race/ethnicity and insurance status. Matern Child Health J. 2014;18(6):1413-22.

26. Bailey BA, Daugherty RA. Intimate partner violence during pregnancy: incidence and associated health behaviors in a rural population. Matern Child Health J. 2007;11(5):495-503.

27. El-Bassel N, Gilbert L, Wu E, Go H, Hill J. Relationship between drug abuse and intimate partner violence: a longitudinal study among women receiving methadone. Am J Public Health. 2005;95(3):465-70.

28. Gilbert L, El-Bassel N, Chang M, Wu E, Roy L. Substance use and partner violence among urban women seeking emergency care. Psychol Addict Behav. 2012;26(2):226-35

29. Udo IE, Lewis JB, Tobin JN, Ickovics JR. Intimate partner victimization and health risk behaviors among pregnant adolescents. Am J Public Health. 2016;106(8):1457-9.

30. Agrawal A, Ickovics J, Lewis JB, Magriples U, Kershaw TS. Postpartum intimate partner violence and health risks among young mothers in the United States: a prospective study. Matern Child Health J. 2014;18(8):1985-92.

31. Westdahl C, Milan S, Magriples U, Kershaw TS, Rising SS, Ickovics JR. Social support and social conflict as predictors of prenatal depression. Obstet Gynecol. 2007;110(1):131-40.

32. Dole N, Savitz DA, Siega-Riz AM, Hertz-Picciotto I, McMahon MJ, Buekens P. Psychosocial factors and preterm birth among African American and white women in Central North Carolina. Am J Public Health. 2004;94(8): 1358-65.

33. Gavin AR, Melville JL, Rue T, Guo Y, Dina KT, Katon WJ. Racial differences in the prevalence of antenatal depression. Gen Hosp Psychiatry. 2011; 33(2):87-93.

34. Breiding MJ, Chen J, Black MC. Intimate partner violence in the United States - 2010. Atlanta, GA: National Center for Injury Prevention and Control, Centers for Disease Control and Prevention. 2014. Available at: https://www.cdc.gov/violenceprevention/pdf/cdc_nisvs_ipv_report_2013_ v17 single_a.pdf. Accessed 15 Sept 2018.

35. Stockman JK, Hayashi H, Campbell JC. Intimate partner violence and its health impact on ethnic minority women. J Women's Health. 2015;24(1):62-79.

36. Goldenson J, Geffner R, Foster SL, Clipson CR. Female domestic violence offenders: their attachment security, trauma symptoms, and personality organization. Violence Vict. 2007;22(5):532-45.

37. Langhinrichsen-Rohling J, Misra TA, Selwyn C, Rohling ML. Rates of bidirectional versus unidirectional intimate partner violence across samples, sexual orientations, and race/ethnicities: a comprehensive review. Partner Abuse. 2012;3(2):199-230.

38. Temple JR, Weston R, Marshall LL. Physical and mental health outcomes of women in nonviolent, unilaterally violent, and mutually violent relationships. Violence Vict. 2005;20(3):335-59.

39. Palmetto N, Davidson LL, Breitbart V, Rickert VI. Predictors of physical intimate partner violence in the lives of young women: victimization, perpetration, and bidirectional violence. Violence Vict. 2013;28(1):103-21.

40. Lewis JB, Sullivan TP, Angley M, Callands T, Divney AA, Magriples U, et al. Psychological and relational correlates of intimate partner violence profiles among pregnant adolescent couples. Aggressive Beh. 2017;43(1):26-36.

41. Buzi RS, Smith PB, Kozinetz CA, Wiemann CM. Pregnant adolescents as perpetrators and victims of intimate partner violence. J Interpers Violence. 2017; ePub ahead of print

42. Haynie DL, Farhat T, Brooks-Russell A, Wang J, Barbieri B, lannotti RJ. Dating violence perpetration and victimization among US adolescents: prevalence, patterns, and associations with health complaints and substance use. J Adolesc Health. 2013;53(2):194-201.

43. Milan S, Lewis J, Ethier K, Kershaw T, Ickovics J. Relationship violence among adolescent mothers: frequency, dyadic nature, and implications for relationship dissolution and mental health. Psychol Women Q. 2005;29(3):302-12.

44. Tzilos GK, Grekin ER, Beatty JR, Chase SK, Ondersma SJ. Commission versus receipt of violence during pregnancy: associations with substance abuse variables. J Interpes Violence. 2010;25(10):1928-40.
45. Hellmuth JC, Gordon KC, Stuart GL, Moore TM. Women's intimate partner violence perpetration during pregnancy and postpartum. Matern Child Health J. 2013;17(8):1405-13.

46. Ickovics JR, Earnshaw V, Lewis JB, Kershaw TS, Magriples U, Stasko E, et al. Cluster randomized controlled trial of group prenatal care: perinatal outcomes among adolescents in new York City health centers. Am J Public Health. 2016;106(2):359-65.

47. Straus MA, Hamby S, Boney-McCoy S, Sugarman DB. The revised conflict tactics scale (CTS2): development and preliminary psychometric data. J Fam Issues. 1996;17(3):283-316.

48. Charles P, Perreira KM. Intimate partner violence during pregnancy and 1year post-partum. J Fam Violence. 2007;22:609-19.

49. Woolhouse H, Gartland D, Hegarty K, Donath S, Brown SJ. Depressive symptoms and intimate partner violence in the 12 months after childbirth: a prospective pregnancy cohort study. BJOG. 2012;119(3):315-23.

50. Radloff LS. The CES-D scale: a self-report depression scale for research in the general population. Appl Psychol Meas. 1977;1(3):385-401.

51. Sipsma HL, Callands T, Desrosiers A, Magriples U, Jones K, Albritton T, et al. Exploring trajectories and predictors of depressive symptoms among young couples during their transition to parenthood. Matern Child Health J. 2016; 20(11):2372-81.

52. Martinez I, Kershaw TS, Keene D, Perez-Escamilla R, Lewis JB, Tobin JN, et al. Acculturation and syndemic risk: longitudinal evaluation of risk factors among pregnant Latina adolescents in new York City. Ann Behav Med. 2017; ePub ahead of print.

53. Spitzer RL, Kroenke K, Williams JB, Löwe B. A brief measure for assessing generalized anxiety disorder: the GAD-7. Arch Intern Med. 2006;166(10):1092-7.

54. Yali AM, Lobel M. Coping and distress in pregnancy: an investigation of medically high risk women. J Psychosom Obstet Gynecol. 1999;20(1):39-52.

55. Lobel M, Cannella DL, Graham JE, DeVincent C, Schneider J, Meyer BA. Pregnancy-specific stress, prenatal health behaviors, and birth outcomes. Health Psychol. 2008;27(5):604-15.

56. Magriples U, Kershaw TS, Rising SS, Massey Z, Ickovics JR. Prenatal health care beyond the obstetrics service: utilization and predictors of unscheduled care. Am J Obstet Gynecol. 2008;198(1):75.e1-7.

57. Staneva A, Morawska A, Bogossian F, Wittkowski A. Pregnancy-specific distress: the role of maternal sense of coherence and antenatal mothering orientations. J Ment Health. 2016;25(5):387-94.

58. Swan SC, Snow DL. The development of a theory of women's use of violence in intimate relationships. Violence Against Women. 2006;12(11):1026-45.

59. Kernsmith P. Exerting power or striking back: a gendered comparison of motivations for domestic violence perpetration. Violence Vict. 2005;20(2):173-85.

60. Finnbogadóttir H, Dykes AK, Wann-Hansson C. Struggling to survive for the sake of the unborn baby: a grounded theory model of exposure to intimate partner violence during pregnancy. BMC Pregnancy Childbirth. 2014;14:293.

61. Roman NV, Frantz JM. The prevalence of intimate partner violence in the family: a systematic review of the implications for adolescents in Africa. Fam Pract. 2013;30(3):256-65.

62. Felder JN, Epel E, Lewis JB, Cunningham SD, Tobin JN, Rising SS, et al. Depressive symptoms and gestational length among pregnant adolescents: cluster randomized control trial of CenteringPregnancy ${ }^{\circledast}$ plus group prenatal care. J Consult Clin Psychol. 2017:85(6):574-84.

63. Kleiber BV, Dimidjian S. Postpartum depression among adolescent mothers: a comprehensive review of prevalence, course, correlates, consequences, and interventions. Clin Psychol-Sci Pr. 2014;21(1):48-66.

64. Swan SC, Gambone LJ, Van Horn ML, Snow DL, Sullivan TP. Factor structures for aggression and victimization among women who used aggression against male partners. Violence Against Women. 2012;18(9):1045-66.

65. American Congress of Obstetricians and Gynecologists [ACOG]. ACOG Committee Opinion No. 518: Intimate partner violence. Obstet Gynecol. 2012;119(2 Pt 1):412-7.

66. American College of Emergency Physicians [ACEP]. Domestic family violence. 2013. https://www.acep.org/patient-care/policy-statements/ domestic-family-violence/. Accessed 26 July 2017.

67. U.S. Preventive Services Task force [USPSTF]. Intimate partner violence and abuse of elderly and vulnerable adults: Screening. 2016. https://www. uspreventiveservicestaskforce.org/Page/Document/Recommendation StatementFinal/intimate-partner-violence-and-abuse-of-elderly-andvulnerable-adults-screening. Accessed 28 July 2017. 